\title{
Predictors of social identification in group therapy
}

TEGAN CRUWYS ${ }^{1 *}$

NIKLAS K. STEFFENS ${ }^{2}$

S. ALEXANDER HASLAM ${ }^{2}$

CATHERINE HASLAM ${ }^{2}$

MATTHEW J. HORNSEY ${ }^{3}$

CRAIG MCGARTY ${ }^{4}$

DANIEL P. SKORICH ${ }^{2}$

Citation:

Cruwys, T., Steffens, N. K., Haslam, S. A., Haslam, C., Hornsey, M. J., McGarty, C., \& Skorich, D. P. (2020). Predictors of social identification in group therapy. Psychotherapy Research, 30(3), 348-361.

1. Research School of Psychology, Australian National University, CANBERRA ACT 2601

2. School of Psychology, University of Queensland, ST LUCIA QLD 4072

3. UQ Business School, ST LUCIA QLD 4072

4. School of Social Sciences and Psychology, Western Sydney University, PENRITH NSW 2751

*Corresponding author:

1. Dr Tegan Cruwys, tegan.cruwys@anu.edu.au Research School of Psychology, Australian National University, CANBERRA ACT 2601 AUSTRALIA

Acknowledgements: This project was supported by funding from the Australian Research Council (DE160100592 and FL110100199). The funder had no role in the study design, data collection, analysis, interpretation, writing, or decision to publish. We are grateful for the support of Genevieve A. Dingle, Nicole Fox, Hayley McMahon and Tian P. S. Oei. 


\begin{abstract}
Background: Group therapy is a popular and effective format for psychological intervention, and both anecdotal and empirical data consistently point to group dynamics as a primary driver of its benefits. However, to date there has been no systematic investigation of what facilitates an engaged, cohesive group environment. We argue that this is social identification and explore the features of groups that help to build this.

Method: We present two longitudinal studies of group therapy and examine the predictors of social identification. Study 1 was a sample of psychiatric outpatients $(N=103)$ who completed group cognitive behavior therapy. Study 2 was a sample of young women with body shape or weight concerns $(\mathrm{N}=112)$ who completed an eating disorder prevention program.
\end{abstract}

Results: Multilevel analyses indicated that social identification was best predicted by participant fit with the therapy group, specifically the degree to which (1) participants were and perceived themselves to be similar to other group members, and (2) participants met the group therapy eligibility criteria at baseline.

Conclusions: These results show that attending to issues of client fit in group therapy can improve social identification, with implications for reducing client attrition and improving client outcomes.

Keywords: social identity; psychotherapy; mechanisms of change; group processes; group therapy 


\section{Predictors of social identification in group therapy}

A large and growing body of research has indicated that group psychotherapy is an effective format for the delivery of evidence-based interventions (Borek, Abraham, Greaves, \& Tarrant, 2018; Morrison, 2001; Norton \& Hope, 2005; Oei \& Dingle, 2008). Although often promoted as a more cost-effective alternative to one-on-one therapy (e.g., Gould, Buckminster, Pollack, \& Michael, 1995; Tucker \& Oei, 2007), group-based interventions have been found to be just as effective as individual psychotherapy (Cuijpers, van Straten, \& Warmerdam, 2008, McRoberts, Burlingame, \& Hoag, 1998). Group therapy also has other advantages over alternative formats. Most notably, both participants and facilitators of group psychotherapy overwhelmingly nominate group dynamics as a key driver of positive change (Burlingame, McClendon, \& Alonso, 2011). Indeed, Irvin Yalom describes positive group dynamics as “a necessary precondition for effective therapy" (Yalom, 1995, p.50).

Defined variously as group cohesion, group climate, group engagement, or group alliance, this sense of affiliation with the therapy group has long been acknowledged as an ingredient that is critical to the success of group psychotherapy (Marziali, Munroe-Blum, \& McCleary, 1997; Ogrodniczuk \& Piper, 2003; Taube-Schiff, Suvak, Antony, Bieling, \& McCabe, 2007). There is substantial overlap between these different constructs. However, the diversity and breadth of ways in which group dynamics in therapy have been conceptualized may be a hindrance to both theoretical precision and empirical advancement (Cruwys, Haslam, Dingle, Haslam, \& Jetten, 2014a; Hornsey et al., 2007; 2009). In this paper, we advance this literature by drawing upon social psychological theorizing and focus on the construct of social identification, which is the degree to which a person subjectively feels that a group positively informs their self-definition (Postmes, Haslam, \& Jans, 2013). 
There are at least three advantages of utilizing the concept of social identification in group therapy. First, social identification is a construct emerging from a rich theoretical history, informed by the social identity approach (comprised of both social identity theory; Tajfel \& Turner, 1979; and self-categorization theory; Turner, Hogg, Oakes, Reicher, \& Wetherell, 1987). At its heart, this is a model of group processes, and so is particularly well positioned to explain group dynamics in group psychotherapy. Second, by drawing on a concept that has been dominant in the study of social relationships for four decades, we are able to build upon hundreds of empirical studies that have examined the assumptions and implications of social identity in diverse domains (for reviews, see Brown, 2000; Haslam, 2014). Third, this theoretical framework provides clear axioms regarding the determinants and consequences of social identification. Accordingly, as we show below, by applying these in the group therapy context we are able to generate novel hypotheses. This has implications not only for optimizing group therapy, but also advances social identity theorizing by providing a rigorous longitudinal test of its basic tenets.

Empirical evidence that speaks to the importance of social identification for group therapy outcomes has emerged from a number of recent studies. For instance, Cruwys and colleagues (2014b) found that clients with depressive or anxiety disorders who identified strongly with their therapy group experienced greater symptom improvement than those who identified less strongly. Similarly, Meuret and colleagues (2016) found that social identification predicted subsequent improvement in social anxiety symptoms among a sample of patients receiving drug and group psychotherapy treatments for social phobia. And amongst older people at risk of cognitive decline, the benefits of a group reminiscence intervention were more pronounced among those with higher social identification (Haslam et al., 2014). Social 
identification has also been linked to patient outcomes in the context of both eating disorder recovery and weight management groups (McNamara \& Parsons, 2016; Tarrant, Khan, Farrow, Shah, Daly, \& Kos, 2017). Finally, in a group therapy intervention designed to address social isolation (Haslam et al., 2016), social identification predicted improvements in wellbeing outcomes including depression, anxiety, and life satisfaction.

These various studies confirm the value of social identification in improving group therapy outcomes. Indeed, group facilitators across a wide variety of treatment modalities have been encouraged to create an environment conducive to the development of a positive and cohesive group dynamic in order to facilitate participants' identification with the group (Borek \& Abraham, 2018). For instance, one study found that convergence between group members in their ratings of the group climate predicted the degree to which they felt involved and valued in the group (Kivlighan, Li, \& Gillis, 2015). However, what is less clear from the literature is what specifically should be done to facilitate the development of group identification. Techniques that have been suggested include establishing "ground rules" for the group, facilitating more interaction among group members, creating names for the group, or encouraging self-disclosure, all of which are thought to improve retention and client outcomes (Burlingame, McClendon, \& Alonso, 2011; Roark \& Sharah, 1989). However, no systematic studies exist to verify these suggestions. The aim of the present research is to establish determinants of social identification in group psychotherapy that are generalizable across treatment modalities.

Outside of the psychotherapy literature, social psychologists have emphasized the importance of contextual factors in determining social identification. More specifically, research has focused on how and when people choose to categorize themselves and others in terms of a particular group membership. In this context, the degree of fit between the individual and the 
group has emerged as a particularly important variable (Oakes, 1987; Oakes, Haslam \& Turner, 1994; after Bruner, 1959). The concept of fit has two primary dimensions. The first is known as comparative fit, which refers to the degree to which members of a particular group are perceived to be more similar to one another than they are to members of other groups (Turner, 1985; after Rosch, 1978). Critically, these perceptions of similarity are informed by dimensions relevant to the nature of the group. Accordingly, in the therapy group context, we might expect that group members' symptom profiles would be a stronger influence on perceptions of similarity than (say) their age or religion (although there are contexts in which these variables could become more important; e.g., if the therapy was being conducted in a church-run residential care home). The second component of fit is known as normative fit. This refers to the match between a perceiver's content-related expectations for the group, in terms of its norms, behaviours, beliefs, and attitudes, and the reality that he or she observes (Oakes, Turner, \& Haslam, 1991). In the therapy group context, an example of normative fit would be the degree to which a person's symptom profile matches the stated purpose and focus of the therapy group. These two forms of fit are represented schematically in Figure 1.

Experimental studies have provided support for comparative fit and normative fit as determinants of social self-categorization. For example, Blanz (1999) investigated comparative and normative fit in three studies. Targets were more likely to be categorized as members of the same group when they both (a) expressed very similar opinions to one another (comparative fit) or (b) expressed opinions consistent with participants' existing expectations of a group's attitudes (normative fit; see also Doosje et al., 1998; Oakes, Haslam, Morrison, \& Grace, 1995; Klauer \& Ehrenberg, 2005; Wegener \& Klauer, 2004). However, evidence of this form has been garnered primarily in laboratory contexts, and has focused predominantly on moment-to-moment 
shifts in identification (i.e., social self-category salience). The relevance of these factors to social identification over the longer term, and to the group psychotherapy context in particular, is therefore yet to be established. Furthermore, the existing literature says little about what these determinants mean in operational terms.

A small body of work has examined the development of social identification over time in small groups (e.g., Postmes, Haslam, \& Swaab, 2005; Meeussen, Delvaux, \& Phalet, 2014). Particularly relevant is work by Jans, Leach, Garcia, and Postmes (2014), which used both experimental and longitudinal designs to demonstrate that the more interaction occurs within a group, the more social identification among group members converges over time. Although not explicitly examining the role of comparative and normative fit in the formation of social identity, this research nevertheless provides important evidence that social identification, despite typically being measured in terms of individuals' self-perceptions, is in fact a group process.

\section{The current project}

The present research examined fit as a predictor of social identification in group therapy. We utilized two very different evidence-based group therapy interventions: first, a sample of adults $(N=103)$ with a diagnosis of an affective disorder, who completed a cognitive-behavioral group therapy program targeting either depression or anxiety (Oei, 2011). The second was a sample of young women $(N=112)$ with body shape or weight concerns, who completed an eating disorder prevention group program (The Body Project; Stice, Rohde, \& Shaw, 2013). Importantly, we do not examine the link between social identification and therapy outcomes here, as this is already well-established, including for these specific interventions (Cruwys et al., 2014b; Cruwys et al., 2015). However, to date there has been no examination of the predictors of social identification in group therapy. 
We operationalized comparative fit in terms of similarity between group members. In Study 1, we used a measure of perceived similarity: the degree to which clients perceived members of their treatment group to be relatively homogeneous at the commencement of therapy. In Study 2, we used a measure of actual similarity among group members. In both cases, we anticipated that clients would report higher social identification (by the end of therapy) to the extent that differences between group members were small at the beginning of therapy (the comparative fit hypothesis; $\mathrm{H} 1)$.

We operationalized normative fit in terms of the match between participants and the explicitly stated purpose of the psychotherapy group (i.e., the match between their psychological symptoms and the selection criteria for group participation). Here we anticipated that clients who reported more severe psychological symptoms at baseline specifically on the dimension targeted by the psychotherapy group would report higher social identification by the end of therapy (the normative fit hypothesis, $\mathrm{H} 2$ ).

\section{Study 1}

Study 1 investigated the hypotheses in the context of a clinical population who were completing group cognitive behavior therapy (CBT) for depression or anxiety. To test H1 (the comparative fit hypothesis), we examined the degree to which participants' perceived similarity among group members in the first session of group therapy predicted social identification. Participants were assigned to a depression-focused or anxiety-focused CBT group by their treating psychiatrist based on their primary diagnosis. To test H2 (the normative fit hypothesis), we focused on the severity of participants' depression symptoms because this was the most common diagnosis in the sample. However, the sample was diverse and the majority of participants were experiencing co-morbid symptoms of several mental illnesses. As such, 
participants varied in the "match" between their symptom profile and their assigned therapy group. This is typical of the real-world settings in which group therapy is conducted. Here we predicted an interaction between depression symptoms severity and CBT group type, such that more severe depression symptoms would be positively associated with social identification in the depression-focused group, but negatively associated with social identification in the anxietyfocused group.

\section{Method}

\section{Participants and Design}

Participants were 103 outpatients at a private psychiatric hospital ( $72 \%$ female) aged 18 $70\left(M_{\text {age }}=45.43 ; S D=12.52\right)$. Participants were predominantly born in Australia $(70.9 \%)$ and spoke English as their primary language (89.3\%). The sample was diverse in the highest level of education: $34.4 \%$ had completed a university degree, $13.6 \%$ had a vocational certificate or diploma, and 23.3\% had completed high school. All participants had received a primary diagnosis of either a mood disorder (most commonly Major Depressive Disorder) or an anxiety disorder (most commonly Generalised Anxiety Disorder) from their treating psychiatrist. Participants were not excluded on the basis of comorbidity and $56 \%$ of participants had more than one diagnosis. Data on concurrent treatment was incomplete, but approximately $85 \%$ of the sample were in receipt of psychopharmacological medication (most commonly antidepressants).

Eligibility criteria were that participants were participating in group CBT for depression or anxiety as outpatients, and did not meet one of the following exclusion criteria: (1) diagnosis of intellectual disability or a developmental disorder; (2) history of organic-based cognitive dysfunction; (3) acute risk of suicide; and (4) a general medical problem that would 
contraindicate treatment. Ethics approval was obtained and participants provided informed written consent.

CBT group sessions were conducted in accordance with a manualized program for eight half-day (approx. 3.5 hour) sessions with 6-12 participants (Oei, 2011). Sessions were held twice-weekly and included activities such as thought challenging and behavioral experiments. Groups were co-facilitated by a registered psychologist who held doctorate qualifications in clinical psychology, and a psychiatric nurse who was experienced in the theory and application of group CBT. Participants were required to attend a minimum of five of the eight sessions in order to be retained in the research.

\section{Measures}

Participants completed a questionnaire at the beginning $(\mathrm{T} 1=$ during the first day of therapy, after members had the opportunity to meet one another and hear about their reasons for attendance) and the end of the CBT program (T2 = during the final day of therapy). The effectiveness of the intervention and full measures are reported elsewhere (Dwyer et al., 2011; Cruwys et al., 2014b).

Social identification. Seven items were used to measure identification with the therapy group (adapted from Hinkle, Taylor, Fox-Cardamone, \& Crook, 1989), e.g. "I feel strong ties to this group", "I am glad to belong to this group", and "I identify with this group." Prior studies have found these items to be valid and reliable $(\alpha=.85)$ measures of social identification (Hinkle et al., 1989; Leach et al., 2008), with reliability confirmed in this sample $(\alpha=.85)$. Responses were measured on a seven-point scale from 1 ("not at all") to 7 ("very much"). The T2 measure of social identification was used as the dependent variable. 
Perceived similarity. Five items were used to measure participants' perceptions that members of the therapy group were similar to one another. These were adapted from socialpsychological measures of homogeneity (e.g., "Members of this group are similar to each other" and "Members of this group are different from each other" [reverse scored]; Campbell, 1958, Park \& Judd, 1990). Participants responded on a seven-point scale from 1 ("not at all") to 7 ("very much"). The reliability of this scale was lower than is desirable $(\alpha=.63)$, however, removing any individual item did not improve the reliability except for the reverse-scored item, and so the decision was made to retain the full scale as originally intended. The T1 measure of perceived similarity was used as the operationalization of comparative fit (H1 predictor).

Depression symptom severity. The 20-item Zung Self-Rating Depression Scale was used to measure severity of current depression symptoms (Gabrys \& Peters, 1985; Zung, Richards, \& Short, 1965), e.g., "I get tired for no reason" and "I feel downhearted, blue and sad". Responses were measured on a four-point scale from 1 ("A little of the time") to 4 ("All of the time"). Previous studies have found this measure to be valid and adequately reliable ( $\alpha=.79$; Knight, Waal-Manning, \& Spears, 1983), with reliability confirmed in this sample $(\alpha=.85)$. The T1 measure of depression symptoms severity was used as the operationalization of normative fit in interaction with group-type assignment (H2 predictor).

\section{Results}

A two-level mixed effects model in $\mathrm{R}$ was used to test the hypotheses using packages lmer4, r2glmm and effects (Bates, Mächler, Bolker, \& Walker, 2015; Fox, 2003; Jaeger, Edwards, Das, \& Sen, 2017). Participants $(N=103)$ were nested within therapy groups $(N=27 ; 13$ depression groups and 14 anxiety groups). The null model included random intercepts for group and participant. Intra-class correlations in the null model indicated that differences between 
participants accounted for $42 \%$ of the variance in social identity; differences between groups accounted for $5 \%$ of the variance in social identity (with 53\% residual variance).

To assess H1, our indicator of comparative fit, perceived similarity, was added to the model. Model 1 was a significantly better fit for the data than the null model, $\chi^{2}(1, N=103)=$ $9.86, p=.001$. In line with $\mathrm{H} 1$, perceived similarity positively predicted social identification with the therapy group, $\beta=.31, p=.001$ (see Figure 2).

Model 2 added our indicator of normative fit to the model, that is, the interaction of group type and depression symptom profile, along with their main effects, were entered simultaneously. Model 2 was a significantly better fit than the null model, $\chi^{2}(4, N=103)=14.79$, $p=.005$. The main effect of therapy group type was non-significant, $\beta=.19, p=.378$. The main effect of depression symptom severity was marginally significant, $\beta=.56, p=.059$, however this was qualified by a significant interaction between therapy group type and depression symptom severity, $\beta=-.38, p=.048$ (as predicted by H2). As can be seen in Figure 3, this effect was such that participants whose symptom profile was most consistent with the stated focus of their therapy group (e.g., high depression severity in a depression group, or low depression severity in an anxiety group) reported higher identification with the therapy group. The final model is summarized in Table 1.

\section{Discussion}

This study first sought to examine the impact of comparative fit - operationalized in terms of perceived similarity among therapy group members — on clients' social identification with their therapy group. Consistent with H1, participants who felt that members of the group were similar to one another at the beginning of therapy were more likely to identify strongly with that therapy group at the end of treatment. This finding is consistent with the theoretical 
predictions about the contextual factors which make social identification more likely (Oakes et al., 1991, 1994). More specifically, when an observer perceives there to be relatively high similarity among group members (relative to non-group members), the group is more likely to be psychologically categorized as a "whole entity", rather than as a collection of individuals. Put another way, when group members are seen to be similar to one another, the group membership becomes a meaningful, useful lens through which perceivers can understand both themselves and others.

Second, the study also examined the impact of normative fit — operationalized in terms of the match between therapy group members' symptom profile (in terms of depression severity) and their assignment to a depression- versus anxiety-focused therapy group — on their identification with that therapy group. Consistent with H1, participants were more likely to identify with their CBT group to the extent that they perceived the group to be a good fit with their personal circumstances. As a corollary, participants whose symptom profile was not characteristic of their therapy group (i.e., mild depression in a depression-focused group, or severe depression in an anxiety-focused group) were less likely to identify with the therapy group. This finding is particularly telling because depression is known to be negatively associated with social identification in general (e.g., Cruwys et al., 2014a; Sani et al., 2012). That is, the fact that depression symptoms were only negatively associated with social identification in anxiety-focused therapy groups, not in depression-focused therapy groups, suggests that this general negative association between depression and social identification is unlikely to be due to a general inability of depressed people to identify with groups, but rather, to be an issue related to fit. 
This first study had several strengths, including its longitudinal design, ecologically valid setting, and clinical population. However, it also had several limitations. First, Study 1 did not look at the evolution of social identification over time, but only at the end of therapy. Examining the trajectory of social identification across the course of therapy would provide further insight into when and how comparative and normative fit are important in the development of social identification. Second, the psychotherapy groups were run more intensively than is typical, which may have amplified the role of group dynamics. There would be value in replicating this finding in more typical (i.e., less intensive) group psychotherapy formats. Third, Study 1 used a self-report measure to assess perceived similarity at the individual level. This measure was found to have only marginal reliability and also means that the findings might have arisen (at least in part) from common measurement variance. To rule out any influence of common measurement variance, in Study 2 we tested the comparative fit hypothesis using an objectively measured indicator of comparative fit at the group level. We also tested our hypotheses in the context of a different population and therapy modality.

\section{Study 2}

Study 2 aimed to replicate the above findings in the context of an evidence-based group intervention to prevent the development of eating disorders. Specifically, participants completed the Body Project (Stice et al., 2013), a manualized program designed for young women with body shape and weight concerns. Groups were run for one hour per week, which is more typical of group therapy than the intensive format of Study 1.

In contrast to Study 1, here comparative fit was operationalized as the objective similarity to other group members on a salient, observable dimension relevant to the therapy group. Specifically, we calculated the variance among group members in their body mass index (BMI) 
at the beginning of the program. We predicted (H1) that participants in groups with higher comparative fit (greater similarity in BMI) would experience a larger increase in their social identification across the course of the program.

As in Study 1, normative fit was conceptualized in terms of the correspondence between participants' symptom profile and the stated purpose of the therapy group. The Body Project's stated purpose is to "help adolescent girls and young women resist sociocultural pressures to conform to the thin-ideal and reduce their pursuit of thinness". Participants are selected for the program on the basis of body shape and weight concerns. At the same time, though, participants who have clinically significant symptoms of an eating disorder are ineligible because the focus of the program is prevention. In keeping with this recruitment strategy and eligibility criteria, we operationalized normative fit in two ways: as both high internalization of the thin ideal and low eating disorder symptoms. We predicted (H2) that participants who had higher normative fit (high thin ideal internalization, low eating disorder symptoms) would have higher social identification with their therapy group.

Study 2 had a number of advantages over Study 1. First, multiple measurements were taken for each person over time. This allowed changes in social identification to be tracked across the course of therapy. This also provided substantially more statistical power. Second, the study used an objective measure of comparative fit rather than a subjective one. Specifically, (low) comparative fit was operationalized in terms of the actual diversity among members of each group on a relevant and observable characteristic (i.e., variance in BMI). This also meant that comparative fit was operationalized at the level of the group, rather than the individual, which aligns more closely with the way comparative fit is conceptualized theoretically (Oakes et al., 1994; Turner, 1985). Third, conducting a replication with a different intervention and 
population from Study 1 entailed quite different operationalizations of comparative and normative fit, and thereby provided a rigorous test of our conceptual hypotheses.

\section{Method}

Participants. Participants were 112 young women living in Australia aged 15-25 with body shape or weight concerns $\left(M_{\mathrm{age}}=18.99 ; S D=3.12\right)$. The majority $(75 \%)$ of participants had a weight in the healthy BMI range $(M=21.74 ; S D=3.95)$. The majority of the sample were White (66\%), or Asian (21\%), and the majority spoke English at home (87\%). Ethics approval was obtained and participants provided informed written consent.

Design. Participants were recruited through advertisements, posters, and mail-outs to students of a large university campus, as well as to community health services in the surrounding region. The Body Project was run in accordance with the manualized program for four 60 -minute weekly sessions with between five and eight participants (Stice et al., 2013). Groups were cofacilitated by two graduate students in clinical psychology. All facilitators received training in the program as well as weekly supervision from a clinical psychologist.

People were eligible for the program if they were female, aged 15-25 years, and reported experiencing concerns about their body shape or weight. The exclusion criterion was a current eating disorder. Two screening items (from the PHQ; Spitzer, Kroenke, Williams, \& Group, 1999) were asked during a screening interview: "Do you often feel that you can't control what or how much you eat?" and "Do you often eat, within any two-hour period, what most people would regard as an unusually large amount of food?" People who answered "Yes" to both questions were screened using the full PHQ eating disorder screening tool, which is based on the diagnostic criteria for eating disorders (American Psychiatric Association, 2000). Respondents who endorsed three or more items were excluded from the study due to a suspected eating 
disorder, and referred to a clinical psychology clinic for further assessment and psychotherapy. Participants were also screened for anorexia nervosa using body mass index, but no participants were excluded on this basis. Participants were required to attend a minimum of three out of four sessions in order to be retained in the research, and over $90 \%$ of participants had full attendance.

Measures. Participants completed a short one-page questionnaire after each session which included measures of the main variables of interest. In addition, participants completed a longer questionnaire with more extensive outcome measures including demographics, height, and weight, immediately before the first session and immediately after the final session (the effectiveness of the intervention and full measures are reported in Cruwys et al., 2015).

Social identification. The validated single item social identification scale (Postmes et al., 2013) was used to measure identification with the therapy group after each session, "I identify with my body acceptance group". Previous studies have indicated that this single item has comparable psychometric properties to longer social identification scales (Postmes et al., 2013; Reysen, Katzarska-Miller, Nesbit, \& Pierce, 2013). Responses were measured on a seven-point scale from 1 ("not at all") to 7 ("very much").

Eating disorder symptoms. Although the screening procedure aimed to exclude those young women with a clinical eating disorder and refer for individualized treatment, the sample nevertheless exhibited a broad range of (subclinical) eating disorder symptoms. The 26-item Eating Attitudes Test was used to measure severity of eating disorder symptoms (Garner, Olmsted, Bohr, \& Garfinkel, 1982), which includes items such as "I feel that food controls my life" and "I am occupied with a desire to be thinner". Responses are on a six-point scale from 0 ("never") to 5 ("always"). Previous studies have found that this is a valid and reliable $(\alpha=.90)$ screener for clinical eating disorders (Mintz \& O’Halloran, 2000), with reliability confirmed in 
the present sample $(\alpha=.92)$. The T1 measure of eating disorder symptoms was used as the first operationalization of normative fit ( $\mathrm{H} 2$ predictor).

Thin ideal internalization. Thin ideal internalization was assessed using the nine-item "Internalization -General" subscale from the Sociocultural Attitudes Towards Appearance Questionnaire (Thompson, van den Berg, Roehrig, Guarda, \& Heinberg, 2004). Participants responded to items such as "I compare my body to the bodies of people who are on TV" and "I would like my body to look like the people who are in movies" on a five-point scale from 1 (“definitely disagree") to 7 ("mostly agree"). Previous studies have found this scale to be a valid and reliable $(\alpha=.96)$ measure of thin ideal internalization in clinical and non-clinical samples (Calogero, Davis, \& Thompson, 2004; Thompson et al., 2004), with reliability confirmed in the present sample $(\alpha=.88)$. The T1 measure of thin ideal internalisation was used as the second operationalization of normative fit ( $\mathrm{H} 2$ predictor).

\section{Results}

Overall, participants showed an increase in social identification at each session of the program, increasing from $M=4.52$ at the end of Session 1 (T2) to $M=5.78$ at the end of Session 4 (T5). A three-level multi-level model was used to test the hypotheses, in which time-points $(N$ $=524$ observations across 5 timepoints) were nested within participants $(N=112)$, who were nested within intervention groups $(N=18)$. The null model included random intercepts for group and participant. In addition, we allowed for random slopes over time for each participant (allowing for the possibility that individuals may vary in their change trajectories). Intra-class correlations in the null model indicated that timepoint accounted for $4 \%$ of the variance in social identity; differences between participants accounted for 39\% of the variance in social identity; and differences between groups accounted for $12 \%$ of the variance in social identity (with $45 \%$ 
residual variance). ${ }^{1}$ This indicates that a three-level model is appropriate to account for the structure of the data.

Model 1 added our indicator of comparative fit to the null model: the degree of variance in the therapy group in BMI at baseline, as well as its interaction with timepoint. This model significantly improved the prediction of social identification over the null model, $\chi^{2}(3, \mathrm{~N}=524)$ $=55.68, p<.001$. The main effect of BMI variance was non-significant, $\beta=-.04, p=.727$. However, consistent with $\mathrm{H} 1$, the interaction between timepoint and BMI variance was significant, $\beta=-.07, p=.002$. This effect was such that the lower the variance in BMI among their fellow group members, the greater the increase in participants' social identification with the therapy group over the course of therapy (see Figure 4).

To assess H2, our two indicators of normative fit (eating disorder symptoms and thin ideal internalization) were simultaneously added to the model. ${ }^{2}$ Model 2 was a significantly better fit for the data than the null model, $\chi^{2}(3, N=524)=67.86, p<.001$. In line with $\mathrm{H} 2$, baseline severity of eating disorder symptoms negatively predicted social identification with the therapy group, $\beta=-.27, p<.001$ (see Figure 5). By contrast, baseline thin ideal internalisation positively predicted social identification with the therapy group, $\beta=.25, p<.001$ (see Figure 6). The final model is summarized in Table 2.

\section{Discussion}

The results of Study 2 conceptually replicated Study 1 and provided support for both of the hypotheses. Specifically, supporting the comparative fit hypothesis (H1), people experienced a larger increase in their social identification with the therapy group to the extent that they were in groups whose members were more similar on a salient dimension (in this case, BMI). In addition, supporting the normative fit hypothesis (H2), participants whose symptom profile was 
closer to the explicit eligibility criteria for therapy (in this case, having high thin ideal internalization or low eating disorder symptoms) went on to identify more strongly with the therapy group.

Importantly, we do not propose that the variables of weight, thin ideal internalization, or eating disorder symptoms are generally related to therapy group identification. Instead, these constructs were operationalizations of fit in the context of this specific therapeutic intervention. Indeed, the utility of the social identity approach which informed our hypotheses is apparent from the fact that we were able to predict, a priori, that eating disorder symptoms and thin ideal internalization would have opposite effects on social identification with the intervention group (which addressed body and weight concerns). This is despite the fact that these variables are positively correlated in the sample and in the population.

\section{General Discussion}

Two longitudinal studies investigated the determinants of social identification among people taking part in group therapy. Here we drew upon core theoretical principles of the social identity approach that have predominantly been tested in controlled experimental contexts, to derive two hypotheses: (H1) that greater similarity among therapy group members would lead to higher social identification (the comparative fit hypothesis), and (H2) that participants who more closely met the inclusion criteria for the therapy group would have higher social identification (the normative fit hypothesis). Using mixed effects models both hypotheses were confirmed in both studies.

A particular strength of this research was the diversity of the samples and therapies. This produced quite different operationalizations of comparative and normative fit in each of the two studies, which were nevertheless consistent with and derived from theory. For example, 
normative fit was conceptualized in terms of constructs related to weight and eating in Study 2, because in the context of an eating disorder prevention group these are the relevant dimensions on which one would expect participants to evaluate the fit of the group with their needs and experience. By contrast, in Study 1, which was conducted in the context of a CBT group for people with diagnosed depression or anxiety, normative fit was conceptualized as the fit between participants' symptom profile and the stated purpose of their CBT group (depression or anxiety).

Similarly, Study 2 utilized an objective, observable indicator of comparative fit, specifically, the degree of variance in participant BMI within the therapy group. Study 1, on the other hand, utilized a self-report subjective indicator of comparative fit — perceived similarity among members of the therapy group. The fact that theoretically consistent results were obtained across these diverse samples and operationalizations increases our confidence in the generalizability of the findings.

Clinical Implications. There are several implications of this research for clinicians. First, our findings suggest that considerations of client fit with a therapy group are crucial at the recruitment and allocation stage, before group therapy even commences. For instance, therapist decisions like what a group program will be called, how it is advertised, and how clients are screened may all contribute to a person's perception that they (do not) fit with a particular group. Fit between a client's symptom profile and the therapy group is likely to be doubly important for outcomes, both because the intervention will more directly target these symptoms and, as demonstrated for the first time here, because fit facilitates identification with the therapy group (which has, in turn, been found to predict outcomes in prior studies). Perhaps a surprising consequence of this is that severity of clinical symptoms, including depression symptoms, are 
not necessarily a barrier to effective engagement in the group. Instead, the match between client issues and the purpose of the therapy group is paramount.

The second clinical implication from this research is that heterogeneity within a therapy group may be a barrier to engagement. Previously, the evidence has been mixed as to whether having groups that are heterogeneous in terms of diagnosis, experience, and stage of recovery helps or hinders outcomes (Burlingame, Fuhriham, \& Moier, 2003; Lieberman, Wizlenberg, Golant, \& Di Minno, 2005; Nicholas \& Forrester, 1999; Perrone \& Sedlacek, 2000). For instance, one study found that heterogeneity in attachment style increased bonding within the therapy group as whole, but led to poorer engagement for individuals whose own attachment style differed from the group mean (Kivlighan, Lo Coco, Gullo, Pazzagli, \& Mazzeschi, 2017). The present research provides a theoretical framework for answering this question, and suggests that perceived heterogeneity on dimensions relevant to therapy (e.g., weight in an eating disorder prevention group) may be a barrier to identification with the therapy group.

While this emphasis on the importance of fit may seem "anti-diversity" at first glance, it is important to note that these findings speak to diversity in a very specific sense - that is, on symptom-specific features that relate to the purpose of the therapy group. Follow-up analyses examining gender, age, and ethnicity did not find evidence that diversity on these dimensions related to outcomes of therapy. Therefore, diversity and fit need to be evaluated very much in the context of the specific therapy, which, so far as possible, should be tailored to the specific client group. Shared experiences and goals are likely to be more important contributors to subjective similarity than outward characteristics, and it is here that the therapist has a crucial role in shaping group climate and client experiences. 
A third clinical implication, therefore, is for improving attendance and retention in group therapy. Recruitment is notoriously difficult in group therapy, despite evidence that it is at least as effective, and in many cases, more accessible, than one-on-one formats (Renjilian et al., 2001; Swift \& Callahan, 2009). Furthermore, attrition can be a major problem, with client drop-out not only compromising the outcomes of those clients who leave but also damaging group dynamics and accelerating attrition for the other group members who are left behind (Vanderplasschen et al., 2013). However social identification has been found to predict attendance across diverse contexts such as sport, church, and college (Mavor, Platow, \& Bizumic, 2017; Stevens et al., in press; Wakefield, 1995; Yssedyk, Matheson, \& Anisman, 2010). While this study only retained participants if attendance was high in order to prevent this from confounding the results, future research might directly examine the relationship between social identification and attendance in the context of group therapy. If facilitators of group therapy are able to refine their recruitment processes in ways that increase clients' perceived fit in the lead-up to, and in early sessions, the resulting increases in identification with the therapy group may improve attendance across the course of group therapy. These findings point to the need for more investment in developing and applying therapeutic techniques which enhance group engagement, or even those which specifically target building and strengthening social identification, such as the GROUPS 4 HEALTH program (Haslam et al., 2016).

Theoretical Implications. This research also has conceptual implications for social identity and self-categorization theories. The determinants of social identification, as specified by Turner and colleagues (1987), have previously only been empirically verified in the context of highly controlled laboratory experiments (e.g., Blanz, 1999; Reynolds \& Oakes, 2000), that focus on identity salience - that is, the momentary psychological prominence of a particular 
group membership. While these experiments provide an excellent test of the causal role of these determinants, the absence of data verifying these findings outside of the laboratory has limited the translation of these ideas to practice. It is here that the value of the current research program lies - in demonstrating that these ideas are useful and practical in predicting social identification over weeks and months, not merely across minutes, and in a domain where identification can make the difference between good and ill health. Put simply: in better understanding why people identify (or not) in group therapy, we can more effectively engage people in evidence-based health care and improve their health outcomes (for broader discussion of the relevance of this point to a range of health conditions, see Haslam et al., 2018).

Conclusions. In two longitudinal studies with 215 clients receiving group therapy, this project has demonstrated that it is possible to pinpoint specific factors that determine whether or not a person will identify with a particular therapy group. This is obviously important for practitioners and health services around the world that offer group therapy. In this regard, practitioners who facilitate group therapy are regularly confronted with a double-edged sword. On the one hand, it is clear that this format has the capacity to achieve a range of positive outcomes for clients. On the other hand, though, it is apparent that there is a high degree of variability in the success of such groups, and that outcomes are often compromised by difficulties associated with both engaging and retaining clients. What the present studies illustrate is that attention to client fit with the therapy group from the outset may go a long way towards explaining this diversity of outcomes. This fit includes both similarity to other group members and correspondence between group members' own symptom profile and the focus of their therapy group. By attending to these features, clinicians can capitalize on proven principles of social psychology to harness the full potential of group therapy. 
Table 1. Study 1 final model predicting social identification with therapy group.

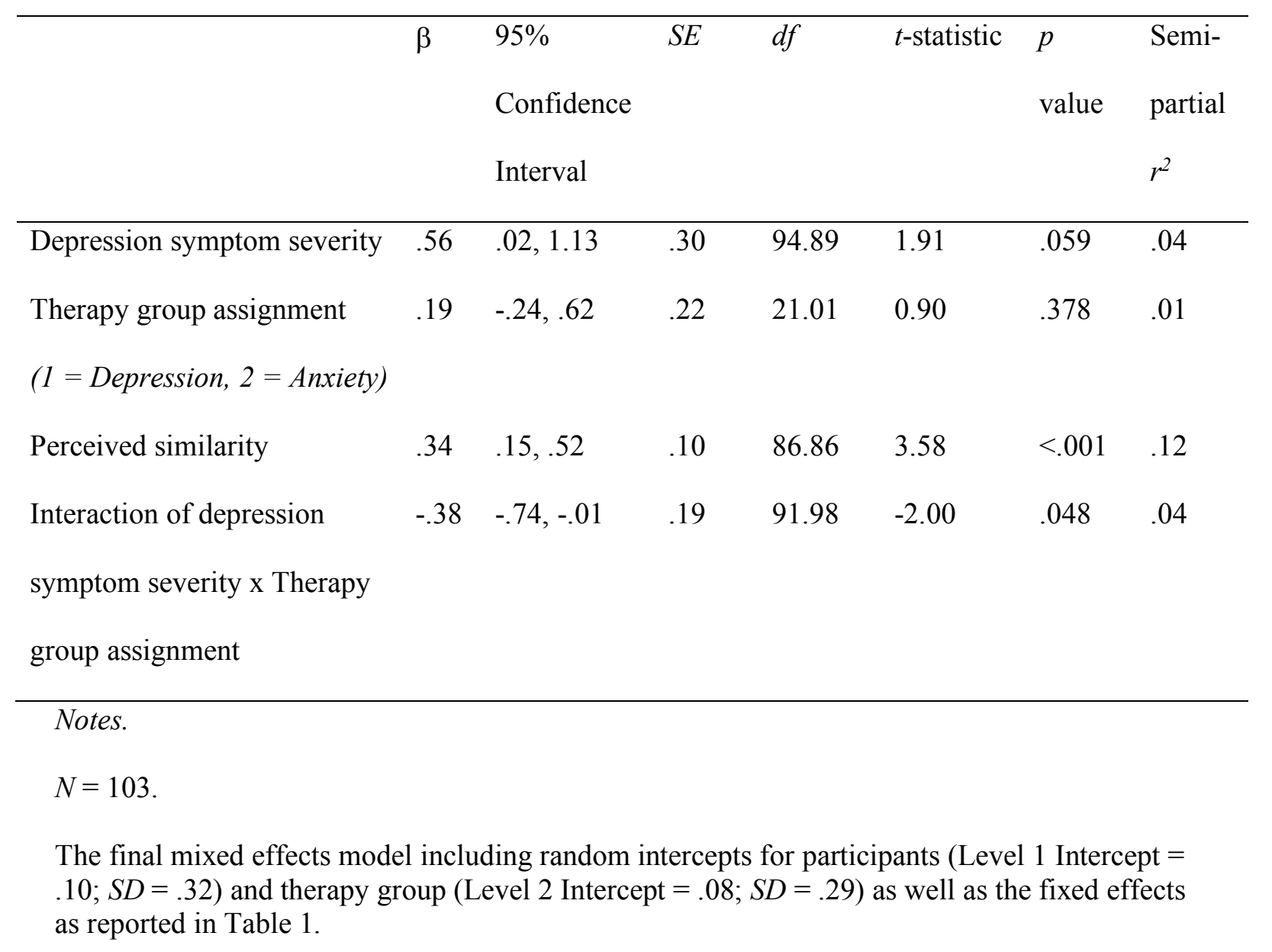


Table 2. Study 2 final model predicting social identification with therapy group.

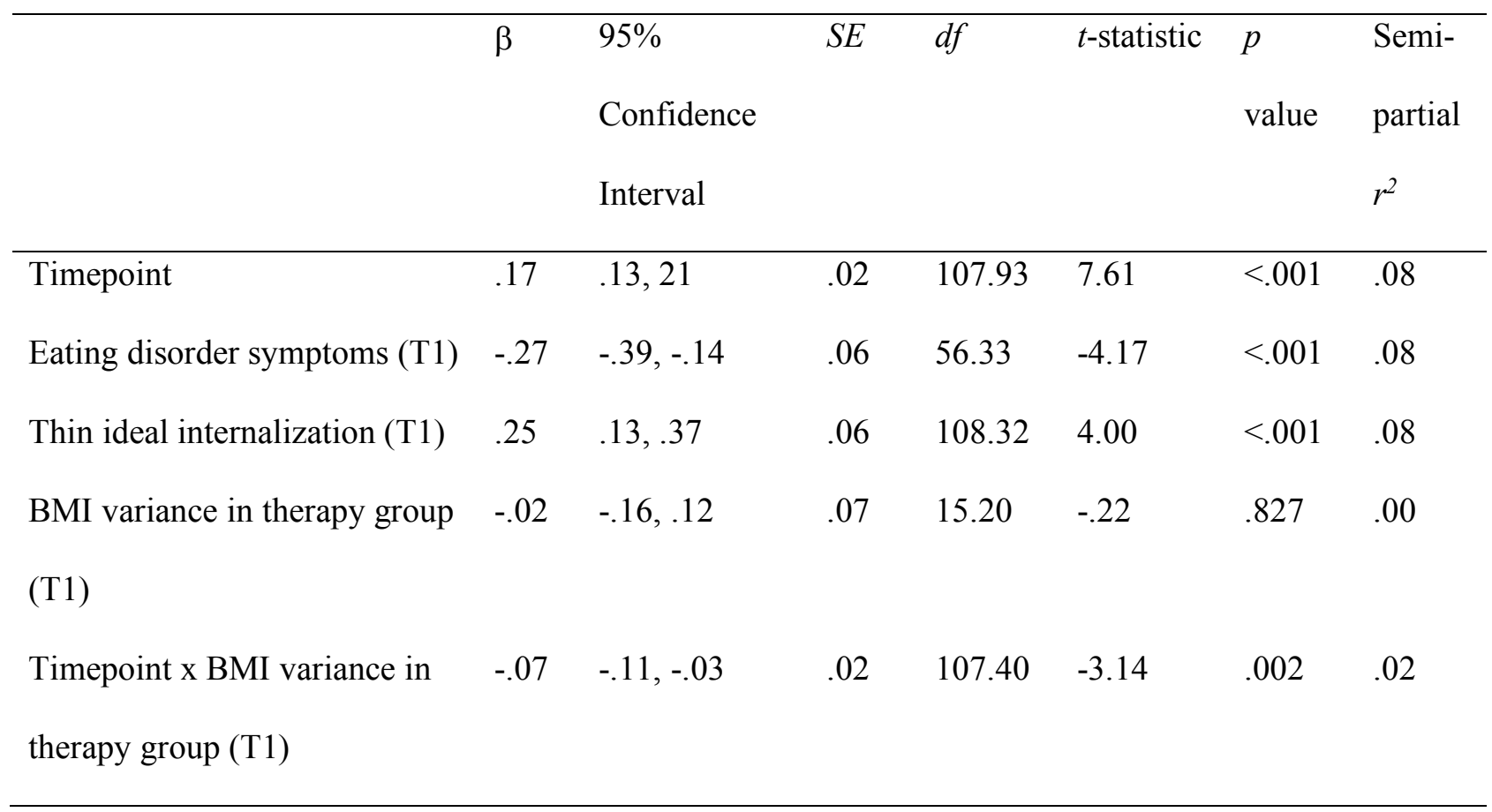

Notes.

$N=112$

The final mixed effects model including random slopes over time for each participant (Level $1=$ $.01 ; S D=.09)$, as well as random intercepts for participants (Level 2 Intercept $=.30 ; S D=.55$ ) and therapy group (Level 3 Intercept $=.00 ; S D=.05)$ as well as the fixed effects as reported in Table 2. 


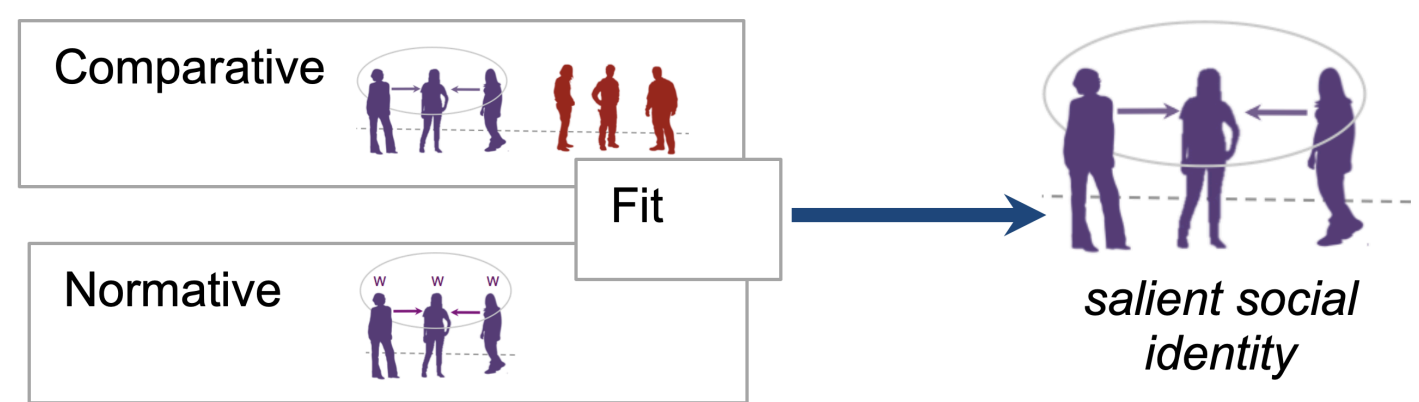

Figure 1. Comparative and normative fit inform the development of social identification.

Note: In any given context, a particular social identity (e.g., as "us women") becomes salient, and hence is a basis for perception and action, partly as a function of the extent to which it is both comparatively and normatively fitting. Comparative fit is enhanced to the extent that differences within a focal group appear to be smaller than differences between that group and other comparison groups. Normative fit is enhanced to the extent that features of the group accord with content-related expectations (for detailed discussion in relation to health contexts, see Haslam et al., 2018, pp. 22-25). 


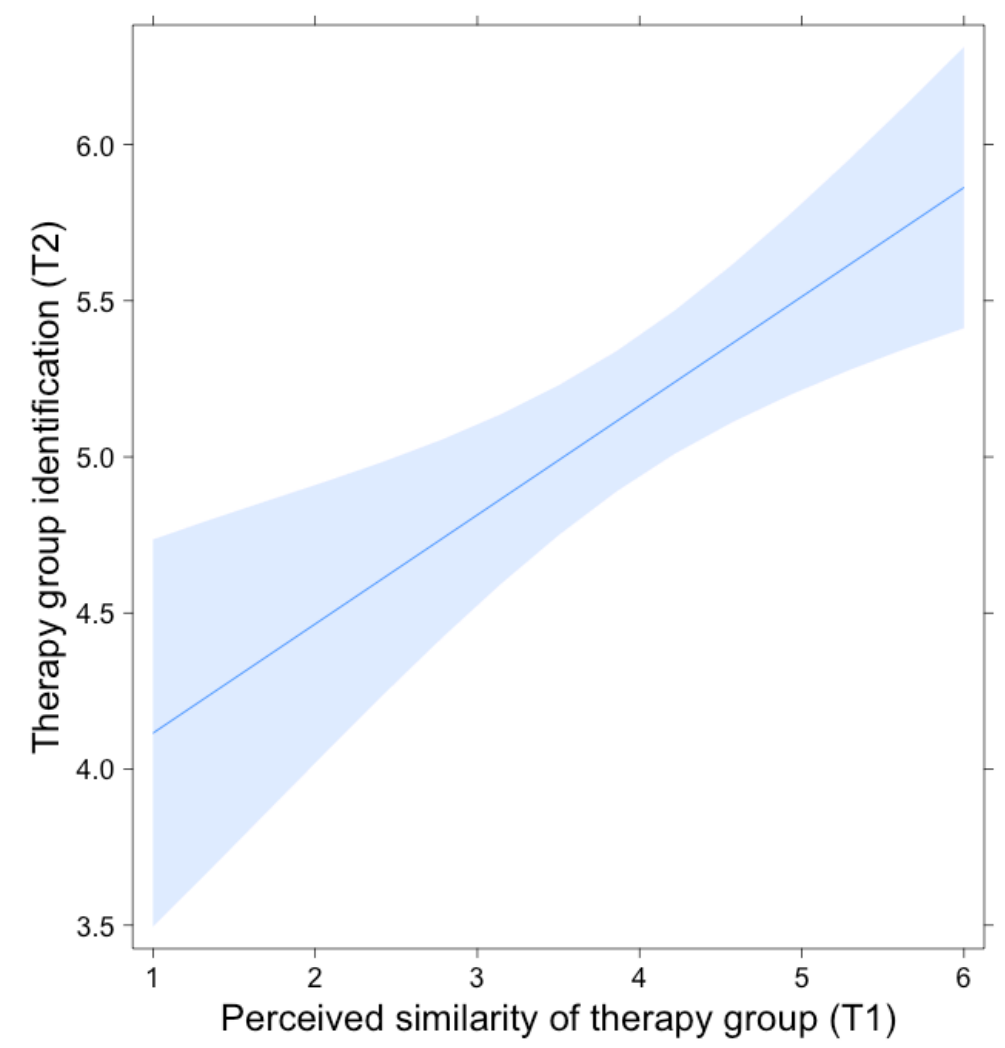

Figure 2. Perceived similarity predicts social identification with a cognitive behavior therapy group. Shaded area represents $95 \%$ confidence interval. 


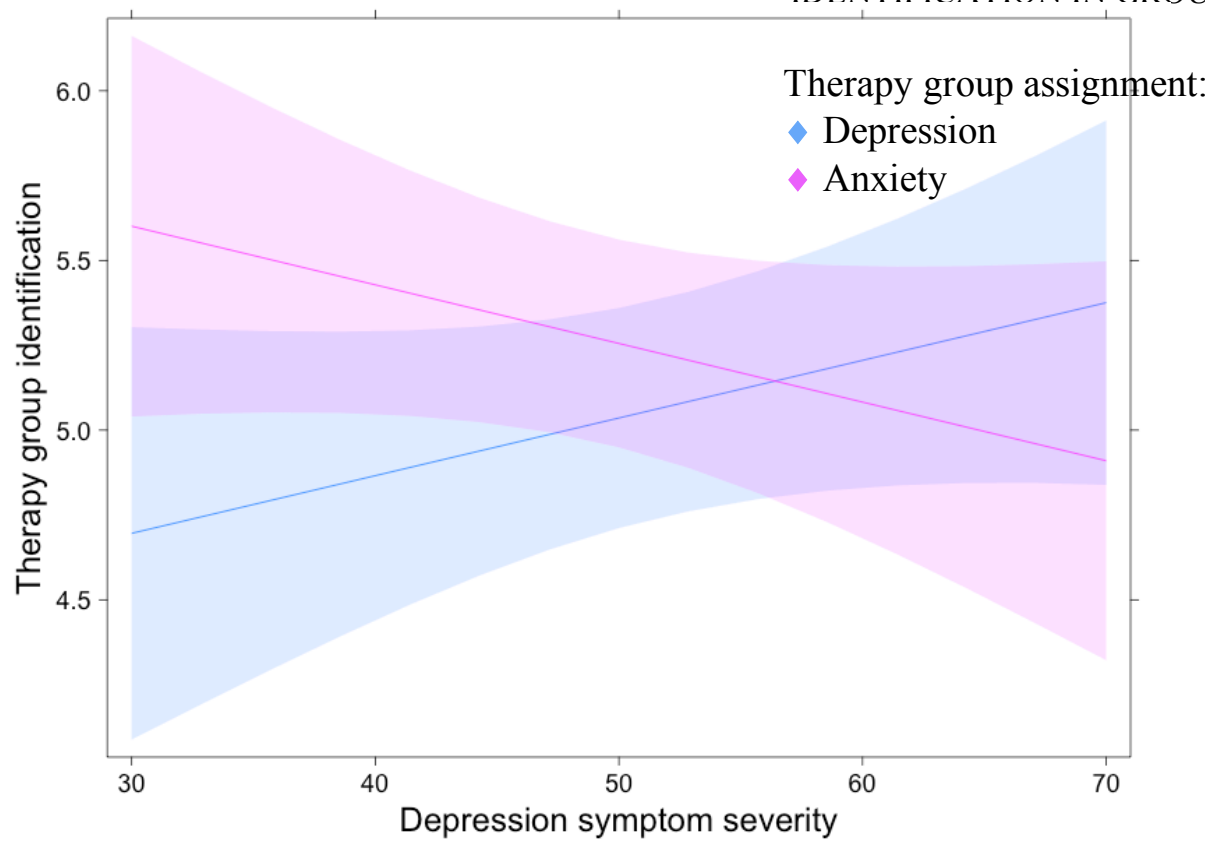

Figure 3. Symptoms profile interacts with therapy type, such that people with more severe symptoms of depression are less likely to identify with an anxiety-focused group and more likely to identify with a depression-focused group. Shaded area represents $95 \%$ confidence intervals. 


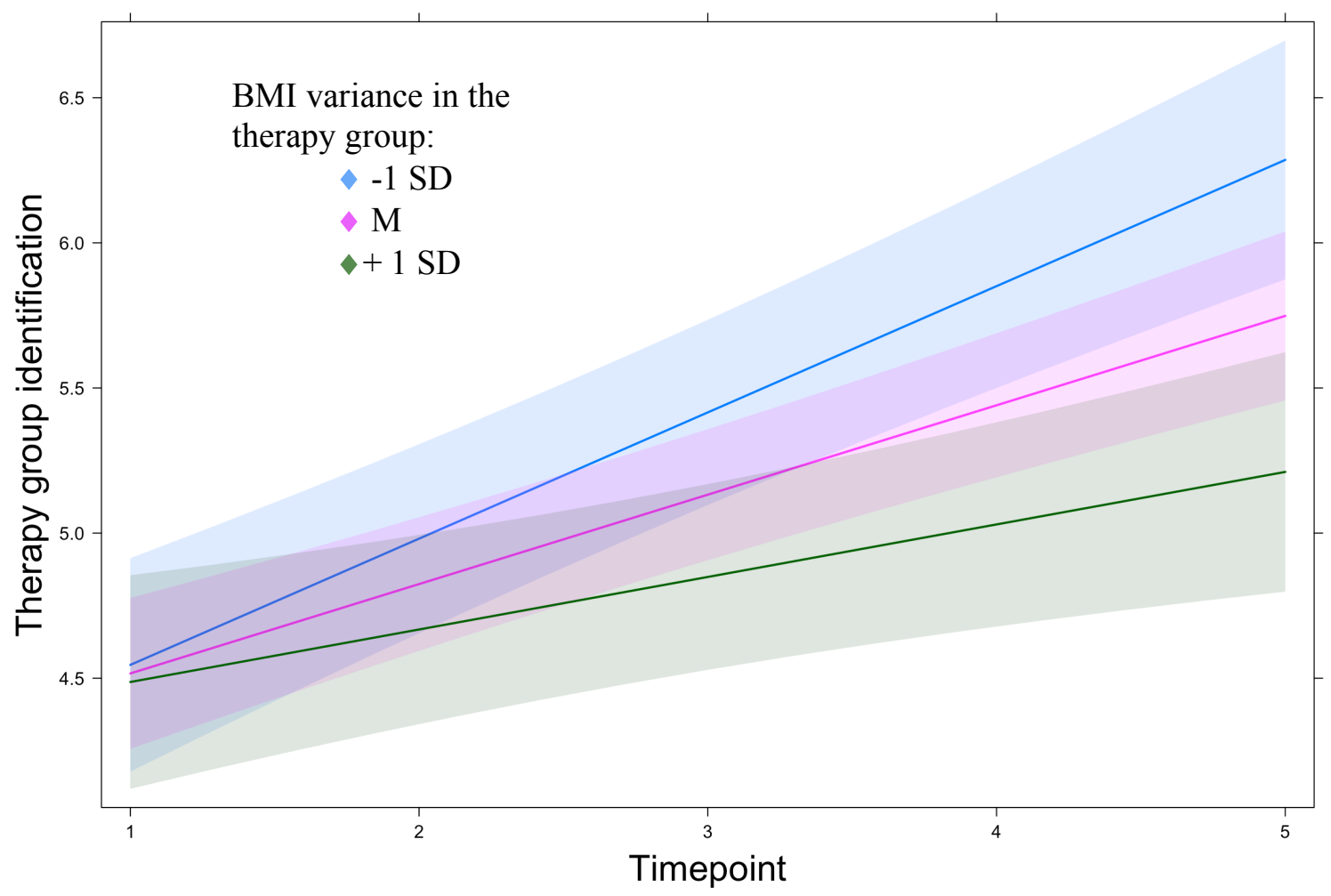

Figure 4. Groups with lower variance in the BMI of their participants see steeper increases in identification over time. Shaded area represents $95 \%$ confidence intervals. 


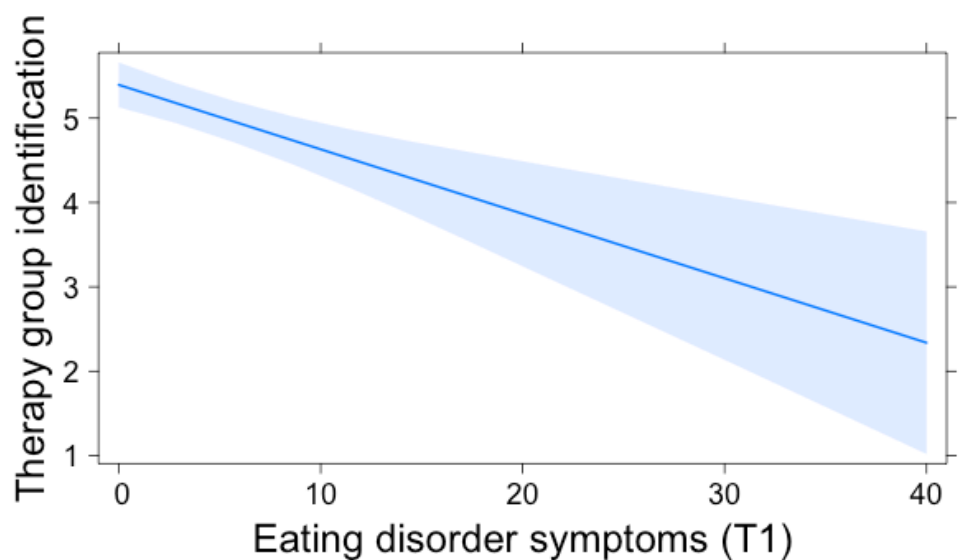

Figure 5. Baseline eating disorder symptoms negatively predict identification with an eating disorder prevention group. Shaded area represents 95\% confidence interval. 


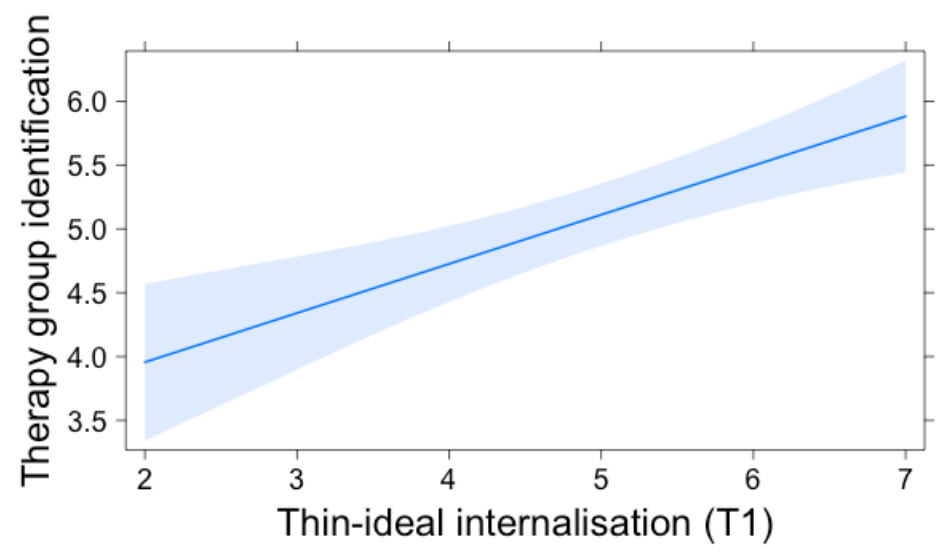

Figure 6. Baseline thin ideal internalization positively predicts identification with an eating disorder prevention group. Shaded area represents 95\% confidence interval. 


\section{References}

American Psychiatric Association. (2000). Diagnostic and Statistical Manual of Mental Disorders, Fourth Edition, Text Revision. Washington, DC: American Psychiatric Association.

Bates, D., Mächler, M., Bolker, B., \& Walker, S. (2015). Fitting linear mixed-effects models using lme4. Journal of Statistical Software, 67(1). https://doi.org/10.18637/jss.v067.i01

Blanz, M. (1999). Accessibility and fit as determinants of the salience of social categorizations. European Journal of Social Psychology, 29(1), 43-74.

Borek, A. J., \& Abraham, C. (2018). How do small groups promote behaviour change? An integrative conceptual review of explanatory mechanisms. Applied Psychology: Health and Well-Being.

Borek, A. J., Abraham, C., Greaves, C. J., \& Tarrant, M. (2018). Group-based diet and physical activity weight-loss interventions: A systematic review and meta-analysis of randomised controlled trials. Applied Psychology: Health and Well-Being.

Brown, R. (2000). Social identity theory: past achievements, current problems and future challenges. European Journal of Social Psychology, 30(6), 745-778. https://doi.org/10.1002/1099-0992(200011/12)30:6<745::aid-ejsp24>3.0.co;2-o

Bruner, J. S. (1957) On perceptual readiness. Psychological Review, 64, 123-152.

Burlingame, G. M., McClendon, D. T., \& Alonso, J. (2011). Cohesion in group therapy. Psychotherapy, 48(1), 34-42. http://doi.org/10.1037/a0022063

Burlingame, G. M., Fuhriman, A., \& Mosier, J. (2003). The differential effectiveness of group psychotherapy: A meta-analytic perspective. Group Dynamics, 7(1), 3-12. http://doi.org/10.1037/1089-2699.7.1.3

Calogero, R. M., Davis, W. N., \& Thompson, J. K. (2004). The Sociocultural Attitudes Toward Appearance Questionnaire (SATAQ-3): reliability and normative comparisons of eating disordered patients. Body Image, 1, 193-198. https://doi.org/10.1016/j.bodyim.2004.01.004

Campbell, D. T. (1958). Common fate, similarity, and other indices of the status of aggregates of persons as social entities. Behavioral Science, 3, 14-25

Cruwys, T., Haslam, S. A., Dingle, G. A., Haslam, C., \& Jetten, J. (2014a). Depression and social identity: An integrative review. Personality and Social Psychology Review, 8, 215-238.

Cruwys, T., Haslam, S. A., Dingle, G. A., Jetten, J., Hornsey, M. J., Chong, E. M. D., \& Oei, T. P. S. (2014b). Feeling connected again: Interventions that increase social identification reduce 
depression symptoms in community and clinical settings. Journal of Affective Disorders, 159, 139-146. http://doi.org/10.1016/j.jad.2014.02.019

Cruwys, T., Haslam, S. A., Fox, N. E., \& McMahon, H. (2015). "That's not what we do": Evidence that normative change is a mechanism of action in group interventions. Behaviour Research and Therapy, 65, 11-17. http://doi.org/10.1016/j.brat.2014.12.003

Cuijpers, P., van Straten, A., \& Warmerdam, L. (2008). Are individual and group treatments equally effective in the treatment of depression in adults?: A meta-analysis. The European Journal of Psychiatry, 22(1). https://doi.org/10.4321/S0213-61632008000100005

Doosje, B., Haslam, S. A., Spears, R., Oakes, P. J., \& Koomen, W. (1998). The effect of comparative context on central tendency and variability judgements and the evaluation of group characteristics. European Journal of Social Psychology, 28, 173-184.

Dwyer, L. A., Hornsey, M. J., Smith, L. G. E., Oei, T. P. S., \& Dingle, G. A. (2011). Participant Autonomy in Cognitive Behavioral Group Therapy: An Integration of Self-Determination and Cognitive Behavioral Theories. Journal of Social and Clinical Psychology, 30(1), 24 46.

Fox, J. (2003). Effect displays in R for generalised linear models. Journal of Statistical Software, 8(15), 1-9. https://doi.org/10.1016/j.quageo.2015.06.006

Garner, D. M., Olmsted, M. P., Bohr, Y., \& Garfinkel, P. E. (1982). The Eating Attitudes Test: psychometric features and clinical correlates. Psychological Medicine, 12(4), 871-878.

Gould, R. A., Buckminster, S., Pollack, M. H., \& Michael, W. O. (1995). Cognitive-behavioral and pharmacological treatment for social phobia: A meta-analysis. Clinical Psychology: Science and Practice, 4, 291-306.

Haslam, S. A. (2014). Making good theory practical: Five lessons for an Applied Social Identity Approach to challenges of organizational, health, and clinical psychology. British Journal of Social Psychology, 53(1), 1-20. https://doi.org/10.1111/bjso.12061

Haslam, C., Cruwys, T., Haslam, S. A., Dingle, G., \& Chang, M. X.-L. (2016). Groups 4 Health: Evidence that a social-identity intervention that builds and strengthens social group membership improves mental health. Journal of Affective Disorders, 194, 188-195.

Haslam, C., Haslam, S.A., Ysseldyk, R., McCloskey, L-G., Pfisterer, K., \& Brown, S.G. (2014). Social identification moderates cognitive health and well-being following story- and songbased reminiscence. Aging and Mental Health, 18, 425-34. 
Haslam, C., Jetten, J., Cruwys, T., Dingle, G., \& Haslam, S. A. (2018). The new psychology of health: Unlocking the social cure. Abingdon, UK: Routledge.

Hinkle, S., Taylor, L. A., Fox-Cardamone, D. L., \& Crook, K. F. (1989). Intragroup identification and intergroup differentiation: A multicomponent approach. British Journal of Social Psychology, 28(4), 305-317. http://doi.org/10.1111/j.2044-8309.1989.tb00874.x

Hornsey, M. J., Dwyer, L., \& Oei, T. P. S. (2007). Beyond Cohesiveness: Reconceptualizing the Link Between Group Processes and Outcomes in Group Psychotherapy. Small Group Research, 38(5), 567-592. https://doi.org/10.1177/1046496407304336

Hornsey, M.J., Dwyer, L., Oei, T.P.S., Dingle, G.A. (2009). Group processes and outcomes in group psychotherapy: is it time to let go of "cohesiveness"? International Journal of Group Psychotherapy, 59 (2), 267-278, http://dx.doi.org/10.1521/ijgp.2009.59.2.279.

Jaeger, B. C., Edwards, L. J., Das, K., \& Sen, P. K. (2017). An R2 statistic for fixed effects in the generalized linear mixed model. Journal of Applied Statistics, 44(6), 1086-1105. https://doi.org/10.1080/02664763.2016.1193725

Jans, L., Leach, C. W., Garcia, R. L., \& Postmes, T. (2015). The development of group influence on in-group identification: A multilevel approach. Group Processes \& Intergroup Relations, 18(2), 190-209. http://doi.org/10.1177/1368430214540757

Klauer, K. C., \& Ehrenberg, K. (2005). Social categorization and fit detection under cognitive load: Efficient or effortful? European Journal of Social Psychology, 35(4), 493-516.

Knight, R. G., Waal Manning, H. J., \& Spears, G. F. (1983). Some norms and reliability data for the State-Trait Anxiety Inventory and the Zung Self-Rating Depression scale. British Journal of Clinical Psychology, 22(4), 245-249. https://doi.org/10.1111/j.20448260.1983.tb00610.x

Leach, C. W., van Zomeren, M., Zebel, S., Vliek, M. L. W., Pennekamp, S. F., Doosje, B., \& Ouwerkerk, J. W. (2008). Group-level self-definition and self-investment: A hierarchical (multicomponent) model of in-group identification. Journal of Personality and Social Psychology, 95(1), 144-165.

Lieberman, M. A., Golant, M., Wizlenberg, A., \& Di Minno, M. (2005). The impact of group composition on internet support groups: Homogeneous versus heterogeneous Parkinson's groups. Group Dynamics, 9(4), 239-250. http://doi.org/10.1037/1089-2699.9.4.239 
Marziali, E., Munroe-Blum, H., \& McCleary, L. (1997). The contribution of group cohesion and group alliance to the outcome of group psychotherapy. International Journal of Group Psychotherapy, 47(4), 475-497. http://doi.org/10.1080/00207284.1997.11490846

McNamara, N., \& Parsons, H. (2016). 'Everyone here wants everyone else to get better': The role of social identity in eating disorder recovery. British Journal of Social Psychology, 55(4), 662-680. https://doi.org/10.1111/bjso.12161

McRoberts, C., Burlingame, G. M., \& Hoag, M. J. (1998). Comparative efficacy of individual and group psychotherapy: A meta-analytic perspective. Group Dynamics, 2(2), 101-117. https://doi.org/10.1037/1089-2699.2.2.101

Meeussen, L., Delvaux, E., \& Phalet, K. (2014). Becoming a group: Value convergence and emergent work group identities. British Journal of Social Psychology, 53(2), 235-248.

Meuret, A. E., Chmielewski, M., Steele, A. M., Rosenfield, D., Petersen, S., Smits, J. A. J. J., ... Hofmann, S. G. (2016). The desire to belong: Social identification as a predictor of treatment outcome in social anxiety disorder. Behaviour Research and Therapy, 81(April), 21-34. http://doi.org/10.1016/j.brat.2016.03.008

Mintz, L. B., \& O’Halloran, S. (2000). The Eating Attitudes Test: Validation with DSM-IV Eating Disorder Criteria. Journal of Personality Assessment, 74, 489-503. https://doi.org/10.1207/S15327752JPA7403

Morrison, N., 2001. Group cognitive therapy: Treatment of choice or sub-optimal option? Behavioural and Cognitive Psychotherapy, 29(3), 311-332

Nicholas, M., \& Forrester, A. (1999). Advantages of heterogeneous therapy groups in the psychotherapy of the traumatically abused: Treating the problem as well as the person. International Journal of Group Psychotherapy, 49(3), 323-342.

Norton, P.J., Hope, D.A, 2005. Preliminary evaluation of a broad-spectrum cognitive- behavioral group therapy for anxiety. Journal of Behavior Therapy and Experimental Psychiatry 36, 79-97 http://dx.doi.org/10.1016/j.jbtep.2004.07.002.

Oakes, P. J. (1987). The salience of social categories. In J. C. Turner, M. A. Hogg, P. J. Oakes S. D. Reicher, \& M. S. Wetherell, Rediscovering the social group: A self-categorization theory (pp. 117-141). Oxford: Blackwell. 
Oakes, P. J., Haslam, S. A., Morrison, B., \& Grace, D. (1995). Becoming an in-group: Reexamining the impact of familiarity on perceptions of group homogeneity. Social Psychology Quarterly, 58(1), 52-60. http://doi.org/10.2307/2787143

Oakes, P. J., Haslam, S. A., \& Turner, J. C. (1994). Stereotyping and social reality. Oxford: Blackwell.

Oakes, P. J., Turner, J. C., \& Haslam, S. A. (1991). Perceiving people as group members: The role of fit in the salience of social categorizations. British Journal of Social Psychology, 30(2), $125-144$.

Oei, T. P. S. (2011). A group cognitive behavioural therapy manual for depression. $4^{\text {th }}$ edition. Jakarta, Indonesia: PLP3 University of Indonesia.

Oei, T. P. S., \& Dingle, G. (2008). The effectiveness of group cognitive behaviour therapy for unipolar depressive disorders. Journal of Affective Disorders, 107(1-3), 5-21.

Ogrodniczuk, J. S., \& Piper, W. E. (2003). The effect of group climate on outcome in two forms of short-term group therapy. Group Dynamics, 7(1), 64-76.

Park, B., \& Judd, C. M. (1990). Measures and models of perceived group variability. Journal of Personality and Social Psychology, 59(2), 173-191.

Perrone, K. M., \& Sedlacek, W. E. (2000). A comparison of group cohesiveness and client satisfaction in homogenous and heterogenous groups. Journal for Specialists in Group Work, 25(3), 243-251. http://doi.org/10.1080/01933920008411465

Postmes, T., Haslam, S. A., \& Jans, L. (2013). A single-item measure of social identification: Reliability, validity, and utility. British Journal of Social Psychology, 52(4), 597-617. https://doi.org/10.1111/bjso.12006

Postmes, T., Haslam, S. A., \& Swaab, R. I. (2005). Social influence in small groups: An interactive model of social identity formation. European Review of Social Psychology, 16(1), 1-42.

Renjilian, D. A., Perri, M. G., Nezu, A. M., McKelvey, W. F., Shermer, R. L., \& Anton, S. D. (2001). Individual versus group therapy for obesity: Effects of matching participants to their treatment preferences. Journal of Consulting and Clinical Psychology. US: American Psychological Association. http://doi.org/10.1037/0022-006X.69.4.717

Reysen, S., Katzarska-Miller, I., Nesbit, S. M., \& Pierce, L. (2013). Further validation of a singleitem measure of social identification. European Journal of Social Psychology, 43(6), 463470. 
Roark, A. E., \& Sharah, H. S. (1989). Factors related to group cohesiveness. Small Group Research, 20(1), 62-69. http://doi.org/10.1177/104649648902000105

Sani, F., Herrera, M., Wakefield, J. R. H., Boroch, O., \& Gulyas, C. (2012). Comparing social contact and group identification as predictors of mental health. British Journal of Social Psychology, 51(4), 781-790. http://doi.org/10.1111/j.2044-8309.2012.02101.x

Spitzer, R. L., Kroenke, K., Williams, J. B. W., \& Group, and the P. H. Q. P. C. S. (1999). Validation and Utility of a Self-report Version of PRIME-MD. JAMA: The Journal of the American Medical Association, 282(18), 1737-1744.

Stevens, M., Rees, T., Coffee, P., Haslam, S. A., Steffens, N. K. \& Polman, R. (in press). Leaders promote attendance in sport and exercise sessions by fostering social identity. Scandinavian Journal of Medicine and Science in Sport. doi:10.1111/sms.13217

Stice, E., Rohde, P., \& Shaw, H. (2013). The Body Project: A dissonance based eating disorder prevention intervention. Oxford: Oxford University Press.

Swift, J. K., \& Callahan, J. L. (2009). The impact of client treatment preferences on outcome: A meta-analysis. Journal of Clinical Psychology, 65(4), 368-381.

Tarrant, M., Khan, S. S., Farrow, C. V., Shah, P., Daly, M., \& Kos, K. (2017). Patient experiences of a bariatric group programme for managing obesity: A qualitative interview study. British Journal of Health Psychology, 22(1), 77-93. https://doi.org/10.1111/bjhp.12218

Taube-Schiff, M., Suvak, M. K., Antony, M. M., Bieling, P. J., \& McCabe, R. E. (2007). Group cohesion in cognitive-behavioral group therapy for social phobia. Behaviour Research and Therapy, 45(4), 687-698. http://doi.org/10.1016/j.brat.2006.06.004

Taylor, S. E., Fiske, S. T., Etcoff, N. L. \& Ruderman, A. J. (1978) Categorical and contextual bases of person memory and stereotyping. Journal of Personality and Social Psychology, 36, 778793.

Thompson, J. K., Van den Berg, P., Roehrig, M., Guarda, A. S., \& Heinberg, L. J. (2004). The Sociocultural Attitudes Towards Appearance Scale-3 (SATAQ-3): Development and validation. International Journal of Eating Disorders, 35(3), 293-304.

Tucker, M., \& Oei, T. P. S. (2007). Is group more cost effective than individual Cognitive Behaviour Therapy? The evidence is not solid yet. Behavioural and Cognitive Psychotherapy, 35(1), 77-91. http://doi.org/doi:10.1017/S1352465806003134 
Turner, J. C. (1985). Social categorization and the self-concept: A social cognitive theory of group behaviour. In E. J. Lawler (Ed.), Advances in group processes (vol. 2, pp. 77-122) Greenwich, CT: JAI Press.

Turner, J. C., Hogg, M. A., Oakes, P. J., Reicher, S. D., \& Wetherell, M. S. (1987). Rediscovering the social group: A self-categorization theory. Oxford: Blackwell.

Vanderplasschen W, Colpaert K, Autrique M, Rapp RC, Pearce S, Broekaert E, Vandevelde S. 2013. Therapeutic communities for addictions: a review of their effectiveness from a recovery-oriented perspective. Scientific World Journal, Article ID 427817

Wegener, I., \& Klauer, K. C. (2004). Intrapersonal versus interpersonal fit: When social categories match social context. European Journal of Social Psychology, 34, 567-593.

Yalom, I. D. (1995). Theory and practice of group psychotherapy (5th ed.). New York: Basic Books, Inc. 


\section{Footnotes}

${ }^{1}$ Alternative (two-level) models which predicted social identity at particular timepoints in the program (e.g., at commencement T1 versus at completion T5) were also considered.

Interestingly, the group level (i.e., which intervention group participants were assigned to) accounted for a non-significant proportion of variance in $\mathrm{T} 1$ social identity, but $33 \%$ of variance in T5 social identity. This speaks to the gradual emergence of group processes and is consistent with the findings of Jans and colleagues (2014).

${ }^{2}$ A more complex model, in which the interactions of thin ideal internalization and eating disorder symptoms with one another and with timepoint, was also tested. This was because our hypotheses did not distinguish as to whether normative fit would be associated with the rate of change in identification or with average identification across the course of therapy. However, this more complex model did not include any additional significant predictors or represent a significant improvement in model fit $\chi^{2}(4, \mathrm{~N}=524)=6.99, p=.137$, and thus the simpler model is retained here. 